The Journal of SPORT, 2013, 2(2), 185-215

(C) Kent State University

\title{
The Historical Development and Marketing of Fantasy Sports Leagues
}

\author{
Rick Burton \\ Syracuse University \\ Kevin Hall \\ Syracuse University \\ Rodney Paul \\ Syracuse University
}

\begin{abstract}
By 2013, fantasy sports leagues (and games) were entered into and played by more than an estimated 32-million people (Dwyer, 2013) across American and Canada, and produced a projected economic impact of \$3.1-billion dollars annually (Fantasy Sports Trade Association, 2012). This work seeks to explain both the historical growth and cultural transitions of in-home sport gaming in the United States as well as the technological evolution that drove the appeal of modern 'fantasy sports' and continued enhancement of professional league avidity by developing stronger brand allegiances for leagues such as Major League Baseball (MLB) or the National Football League (NFL).

From a historical standpoint, the term 'Fantasy League' didn't garner popularity until the 1980s, but the concept of fantasy sports gaming can be traced back to the mid-1860s with a simple wooden tabletop contraption that simulated outcome elements of a baseball game (Cooper, 1995). Over the next 150 years, technological and social developments in the areas of in-home re-creation and networked gaming have caused fantasy sports to re-shape sports media coverage, sports marketing (particularly of sports data), fan avidity, technology engagement and general sport discussion.

The impact of these fan-based developments might prove significant and increasingly leagues like the NFL have been forced to ask whether the at-home experience of following professional football (including the owning and managing of fantasy football league teams) is reaching a point where it could replace attending NFL games in person. A sea-change such as that (decreases in NFL game attendance, failure to sell out NFL games, etc.) would potentially threaten lucrative team and league sponsorships, stadium merchandise and concessions (food, beverage, parking, etc.) and possibly even TV network broadcast contracts (by way of diminished ratings and advertising demand).
\end{abstract}




\section{Introduction}

While sport in its simplest form has captivated the interest of varied citizenry for many centuries (dating back at least until 776 B.C. with the creation of the ancient Olympics), the last 150 years has witnessed an increasing desire by fans to review, analyze, collect and manage professional athlete data (i.e., player performance metrics). Further, as technical access to game data and player statistics have become easier to aggregate and manipulate by individuals, media platforms such as magazines, newspapers, radio, television, internet websites and modern social networks, have generated increasingly deeper levels of consumer avidity, purchase and consumer control of the sport product. As demand for accurate statistical data has grown, the marketing of fantasy sport gaming has also evolved. Sports-related games have moved in a deliberate technological progression from simple wooden table games to "simulated team management" via cardboard games (Edelman, 2012) to computer simulation of imagined games to modern-day management of 'fantasy teams' (comprised of actual players) playing in 'fantasy leagues'.

In its contemporary form, fantasy sport can be defined as playing a game in which linked participants take on the roles of team "managers" or "general managers" and manipulate an aggregated "team" of players whose real-world performances generate point values that determine the outcome of head-to-head matchups. Play usually begins with a process known as a player draft wherein the consumer (acting as team owner) assembles a team made up of actual players from a professional league. This 'owner' then competes against other "owners" or "managers" in a fantasy league. Fantasy team owners earn points based on the real life statistics the players on their rosters generated in real league games. These points accumulate across multiple games creating a single game performance where the fantasy team owner wins or loses in head-tohead competition. Scoring systems vary across leagues, with players earning points for a variety of game statistics. For example, in fantasy football leagues, running backs and wide receivers may earn a point for every 10 yards gained carrying or receiving the ball and 6 points for each touchdown scored. 
In general, leagues consist of 8-12 teams and are comprised of groups of close friends or a grouping of relative strangers. Some leagues require entry fees with payouts to victors on a weekly and/or seasonal basis. Other fantasy leagues (including many popular online versions of fantasy sports) have no entry fee or cash prizes associated with participation. In either scenario, the ultimate goal of the fantasy owner is to win the fantasy league championship. In some leagues, owners compete head-to-head with another owner on a weekly basis, while other leagues highlight the entire season through a "rotisserie"-style framework where overall points or leading certain categories are key to overall fantasy owner victory. In prize leagues (monetary or otherwise), some are structured as winner-take-all, while others offer monetary prizes weekly or daily for individual team performance.

Whether there are monetary prizes or not, fantasy sports have led to key financial gains for websites who offer management of these leagues and thus attract key advertising dollars. Other websites charge monthly or annual fees (in addition to advertising revenue they generate) for their information about fantasy players and teams while television networks produce weekly or daily shows about fantasy sports. Finally, many of the professional leagues (such as the NFL) have embraced fantasy sports as part of their marketing plans.

As Strasser (1989, p. xi) noted, "Networks of human relationships are a fundamental aspect of culture" and these networks have been "essential to the development of what may literally be called consumer culture." Thus, stimulating replications of popular cultural events such as professional baseball or football games - be it through playing random-chance table toys, trading baseball cards distributed via tobacco brands or joining fantasy sports leagues - are logical constructions for individuals seeking to broaden their human networks. In writing on the historical evolution of brands, Strasser $(1989$, p. xi) posits that "consumer goods may be understood as artifacts of the new culture" and from this we can infer that sporting consumer goods (i.e., toys, board games, magazines or websites) are relevant cultural products that reflect the evolving interests of a particular age. 


\section{Historical Overview - The Tabletop and Board Game Era}

The roots of fantasy sports stretch to the mid- $19^{\text {th }}$ century and the earliest manufactured in-home games utilized a pinball-like design (Dulken, 2002). In Francis Sebring's 1866 Parlor Base-Ball game, a coin (representing a baseball) would be propelled along a flat wooden surface by a coiled spring (the pitcher) toward a movable flipper (the batter). The batter would then hit the coin into one of several open slots on the playing surface and create a specific outcome of the game-player's at-bat (Reilly, 2005). This format allowed the game player (the consumer) to imagine that the pitcher (the act of propelling the coin) and the batter was anyone known (locally or nationally) to the actual Parlor Base Ball player. Behaviorally, this gave the consumer a sense of controlling the product's usefulness and, in an era that featured increased amounts of leisure time, allowed for a pleasurable relationship with the product and the potential for great sentimental attachment (Strasser, 1989).

Further extensions of baseball's value as a vehicle for consumer attachment can be found in one of the earliest forms of American sports marketing in which mainstream tobacco brands such as "Old Judge, Goodwin Champions and Allen \& Ginter started issuing collectible baseball cards with cigarette packs in the late 1880s" (Burton, 2010a). These black and white cards or later color chromolithographs (Katz, 2009) were keen applications of a consumer product using the new sport and gaming "culture" to engage consumers and further drive brand investments. Since the first "publicly proclaimed professional baseball team had only been established" in 1869 with an "organized league of professional teams" following (McChesney, 1989, p. 52), it suggests the linkage between American sport and consumerism needed less than 20 years for incubation and evidence of professional player-endorsed in-home games (such as Zimmer's Base Ball Game or The Champion Game of Base Ball) and non-endorsed games (like Game of Base-Ball, National League Ball Game and Home Base Ball) would emerge by the dozens between 1869 and 1900 (Cooper, 1995).

In literature, evidence of the individual creating his own baseball team arguably first appears in Mark Twain's 1889 novel $A$ 
Connecticut Yankee in King Arthur's Court wherein Twain's protagonist Hank Morgan organizes a baseball game and places players drawn from King Arthur's peers and court in various fielding positions (Brock, 2010, Burton and Finkel, 2013 in press). Shortly thereafter, Charles Van Loan's 1912 short story, "The Phantom League" (from the book "The Ten-Thousand Dollar Arm") developed a narrative around a part-time baseball scout named Frisbee who is fooled into believing statistics drawn from the Independent Northern New Mexico Baseball League are real. Frisbee then determines he must travel to New Mexico to scout the players who are producing such notable statistics. In truth, as part of a practical joke, an individual named Meeghan is using "a mechanical ball-game device" to produce statistics for imaginary players that correspond to board-game tokens or counters.

Another hoax involving the fabrication of sports data and phantom players would actually make it onto the pages of the $\mathrm{New}$ York Times during the autumn of 1941 when an "imaginative" 35year-old Wall Street stockbroker named Morris Newburger began posing as the sports information director for a mythical institution named Plainfield Teacher's College. Each Saturday, Newburger, posing as sports information director Jerry Croyden, would phone in results from Plainfield's football games giving most of the credit for Plainfield's victory to a non-existent Chinese sophomore halfback named John Chung. Not long afterward, the New York Post columnist Herb Allan was writing in his "College Grapevine" column that "John Chung has accounted for 57 of the 98 points scored by his unbeaten and untied team in four starts. If the Jerseyans don't watch out, he may pop up in Chiang Kai-shek's offensive department one of these days." Hollander (1967) concludes her account of Newburger's charade by noting that "on Saturday afternoons they [Newburger and his associates] would take turns "calling the newspapers and manufacturing press releases about the marvelous feats" (p. 76) taking place at Plainfield. "For the stockbrokers this was certainly no money-making proposition. It was an investment in fun and fantasy. They wanted a winning football team and they got one" (p. 77). 
Twain and Van Loan's literary creations and Newberger's deceitful efforts suggest a period of growing consideration by sports fans to either extend the relevance of sport toys (i.e., the mechanical ball-game device used by Meeghan) or to manipulate actual sports coverage. In each case, there is evidence fans desired to manage game scenarios or outcomes personally. Facilitation for this concept began as early as the mid-1880's when British-born sportswriter Henry Chadwick developed the baseball box score for newspaper readers. This journalistic invention created "in capsule form who played, who won, who lost, who did well and who didn't" (Burton and Finkel, 2013 in press). A few years later in 1883 the first newspaper sports department was created at Joseph Pulitzer's New York World and in 1895 William Randolph Hearst introduced the first distinct sports section in the daily New York Journal. These actions by distinct newspaper brands showed that baseball statistics (i.e., wins, losses, batting averages, home runs), like industrial output, could be measured (McChesney, 1989).

Further, national media coverage of baseball players and even the anointing of players as favored brands (i.e., Mike 'King' Kelly) was leading to "the creation of popular songs such as "Slide, Kelly, Slide" (1883), which emerged as America's first "pop [musical] hit" in 1889 and Ernest Thayer's poem "Casey at the Bat" where actor DeWolf Hopper began performing as Mighty Casey on vaudeville stages in 1889" (Burton, 2010). This meant sport was now covered in great detail by the mainstream media and that players were emerging like breakfast cereal, biscuit and chewing gum brands: as products that, either at the stadium or as re-creations, were affordable for mass audiences and capable of satisfying mass engagement desires (Strasser, 1989).

Ultimately, we can infer that if board games, songs, vaudeville recitations, popular novels or baseball-specific narratives were married with baseball box scores and daily sports coverage of human performance, simple physical simulation games such as Parlor Base-Ball or Major League Indoor Base Ball would lead baseball fans into further manipulating fantasy game simulations by incorporating existing statistics or by creating new statistics of their 
own from the use of randomization devices such as dice, spinners, or cards (Cooper, 1995; Cochran, 2005).

One such invention that would emerge was "National Pastime", a tabletop baseball game designed by Clifford Van Beek and published by Major Games in 1930. Here, using dice and individualized cards, Van Beek's National Pastime was the first game to attempt to accurately simulate the performance of actual major league baseball players (Albert and Bennett, 2001). In contrast, players represented in prior mechanical games all had the exact same chance of all potential batter outcomes (singles, home runs, strike outs, etc.) as every other name in the game player's imagined line-up (Reilly, 2005). National Pastime used real player statistics (or a statistically-directed approach), so Yankees great Babe Ruth would hit more home runs, draw more walks and strike out more than other represented players (Bowman and Zoss, 1989).

The demand for more player-specific outcomes in sports simulation games changed this industry in the years following the introduction of "National Pastime". In 1941, former big league baseball player Ethan Allen sold the Cadaco-Ellis board game company a new game called “All Star Baseball” (McNeil, 2008). Like National Pastime, it used actual player statistics to provide enhanced fantasy game-play. Circular cards represented real-world players and each card was divided into 14 numbered segments (in a pie-chart style). Individual segments represented a possible outcome for the player's at-bat such as Home Run, Walk, Strikeout or Groundout. The size of each outcome segment corresponded with the player's actual statistics (Brock, 2006). Again, the Ruth circular featured a larger home run segment than other big leaguers. When a player was up to bat, their card was placed under a metal spinner. Wherever the spinner landed would create the result of that specific at bat.

APBA Baseball, another baseball game, closely inspired by National Pastime and All Star Baseball, would be introduced to the gaming market by Richard Seitz in 1951 (APBA Games, 2011). It was followed in 1961 by Strat-O-Matic Baseball, which was invented by Bucknell University mathematics major Hal Richman who had begun "to develop the game as an 11-year-old in 1948 after 
becoming dissatisfied with the statistical randomness present in other baseball games of the era" (Edelman, 2012). Richman's game included one playing card for each MLB player with each card providing ratings and results tables that corresponded with dice play (Miller, 2011; Edelman, 2012). Ultimately, Richman "survived money-losing years, royalty demands from [baseball's] players union and challenges from well-heeled competitors as his invention became the leading baseball board game." After inventing games for the NBA, NFL and NHL, he added "advanced versions for baseball that featured ratings for hit-and-run ability, outfielders' throwing arms and pitchers' endurance" (Miller, 2011).

In between Seitz's work in 1951 and Richman's distribution of Strat-O-Matic Baseball in 1961, Harvard professor Bill Gamson, developed The National Baseball Seminar in 1960 and became the first to invent a multi-player fantasy game prototype in which the players, acting as team owners, worked from remote or satellite locations (Allis, 2006). Gamson's concept involved aggregating 25 league members who worked with a "mythical \$100,000 at spring auctions to acquire real players and manage a team in each [of baseball's two] major leagues." When Gamson moved to the University of Michigan in 1962, he brought Seminar (named so the Cambridge, Mass., post office would not think he was "running a bookie operation") with him and he ultimately influenced two individuals, Robert Sklar and Daniel Okrent, who would completely re-shape fantasy sport development through a variety of viral tactics (Allis, 2006).

But Gamson was not alone in stretching the boundaries of fantasy sport development since nearly simultaneously in December 1960, John Burgeson, "a mid-level programmer at IBM in Akron, Ohio invented a form of computerized fantasy baseball" that "presaged the rudimentary concepts of sabermetrics" (Kalb, 2012). By Burgeson's own editing on Wikipedia in January 2009, the retired computer programmer claimed that "an early form of fantasy baseball was coded for an IBM 1620 computer in 1960 by John Burgeson, IBM Akron." According to Kalb (2012), Burgeson's creation was "essentially a digital version of Strat-O-Matic" played on an extremely expensive machine and was decidedly anti-social. 
What it did, though, was allow the computer to "generate outcomes based on the relative strengths and weaknesses of those players' preexisting stats." The significance of this development (or invention) was Burgeson's determination that "quantitative multivariable computer analysis could determine the relative merits of baseball players and figure out who would win a game."

Interestingly, it was a "marbles and nails" primitive pinball board game called Put-N-Take Baseball which was made by Northwestern Products of St. Louis and patented in 1933 that had first inspired John Burgeson to create an imaginary baseball league with his brother Paul in 1948. By 1960, he was able to merge the IBM 1620's "algorithmic alacrity" and turn it into a "little baseball simulator" (Kalb, 2012).

From a marketing standpoint, we can suggest these dedicated (or perhaps extreme) baseball fans, many working in isolation, were mixing simulation concepts with play-at-home toys or game brands like National Pastime, Put-N-Take Baseball, APBA, Strat-O-Matic Baseball and All Star Baseball in order to create more fully evolved fantasy game forms. This growing interest in managing self-created teams and leagues mixed with evolving technology and brand sophistication (Christ and Anderson, 2011) would ultimately lead to the group-engaged gaming concept we now call "fantasy sports".

Kotler (1991) has suggested that a brand is widely defined as a "name, term, sign, symbol, or design or combination of them which is intended to identify the goods or services of one seller or group of sellers and to differentiate them from those of competitors" Building on this, Aaker $(1991,1996)$ has often discussed the concept of strong brands or brand development via segmented industries and product line extensions. Thus, while marketing of toys or games was initially (and primarily) focused on children (and, in particular, boys) during the early to mid- $20^{\text {th }}$ century, emerging statistical access benefitting older baseball fans would sow the seeds for new baseball by-products and loosely-linked networks that started incorporating real-time data and game outcomes. Thus, despite narrow demographic targeting by early toy and board game manufacturers, "fantasy" game-play using actual player statistics started to come of age for an older male demographic during the 1960s and 70s. What 
had been missing up to this point was the ability of "participants to showcase managerial prowess [when] predicting future events" (Huey, 2005; Edelman, 2012).

\section{The Prognosticators, Rotisserie League and Expanded Data Era}

By the early 1960 's, the earliest documentation of what can be considered a future-outcome focused fantasy sport league was starting to emerge. It gained speed in 1963 when Bill "Wink" Winkenbach, a front office employee of the Oakland Raiders organized the "Greater Oakland Professional Pigskin Prognosticators League", or GOPPPL (Essler, 1994). To join the league, individuals were required to meet the following criteria: Administrative affiliation with an AFL franchise, professional journalistic relationship to professional football or to have purchased or sold ten Oakland Raiders season tickets (Schauf, 2010). Winkenbach had been running similar golf and baseball games among his friends since the mid 50's, but GOPPPL is now considered one of the first examples of a fantasy league (Harris, 2003).

Although the fantasy sports concept had only percolated during the 1960s, wider exposure of multi-player gaming would not arrive until 1979. That's when sportswriter Daniel Okrent, a figure many sport historians now consider the "father of fantasy sports", introduced a product he called Rotisserie Baseball (Wulf, 1984). While working as a writer for the now- defunct sports magazine Inside Sports, Okrent drew on his 1965 exposure to Gamson's The National Baseball Seminar (TNBS) from Robert Sklar, his freshman advisor at Michigan. Sklar had participated in TNBS with his Harvard and University of Michigan professor Bill Gamson during the early 60's (Allis, 2006; Edelman 2012) and introduced Okrent to Gamson's concept. From there, Okrent devised the idea of Rotisserie baseball (named after a restaurant, La Rotisserie Francaise, frequented by Okrent) during a flight to Austin, Texas (Walker, 2006). Rather than accruing points directly from individual players as discussed earlier, his scoring system was based on winning individual statistical categories to accrue points; each category won accounts for 1 point. For example, if the players on Team A 
combined to hit 7 home runs and the players on Team B hit 10 home runs, Team B earned the point for the Home run category. Teams would face off head-to-head for a week at a time hoping to win more points and the overall matchup. Players were drafted in an auction style. Managers were given a certain amount of theoretical money to start with and would bid on each player (Eisenberg and Waggoner, 1984). After the first season of Okrent's Rotisserie League, he published an article in Inside Sports entitled "The Year George Foster Wasn't Worth \$36”. The story introduced Okrent's fantasy league to a mass market and triggered the creation of similar leagues across the country (Schwarz, 2004).

At this point, public interest in more complete and alternative sports statistics was rapidly increasing. Before 1977, most baseball statistics available to the public came through newspaper box scores or periodicals such as the Sporting News which provided weekly box scores and team summaries for its baseball readers. However, in 1977, Bill James provided the start of a baseball statistical revolution when he published his Baseball Abstract. This annual book focused on detailed baseball statistics beyond what was traditionally available in newspapers or distributed verbally during baseball or radio broadcasts. James' self-published books developed a strong following (mainly through small advertisements placed in the Sporting News) and, in 1982, his operation was purchased by a media conglomerate and distributed to a much wider audience. His analysis spawned the SABR (Society for American Baseball Research, soon known as Sabermetrics) and the overthrow of traditional baseball statistics. It also led to widespread proliferation of books, magazines, and websites devoted to more detailed analysis of baseball data. Groups such as STATS, Inc. were formed in order to provide content to sports leagues for broader baseball fan consumption. Today, staples of the baseball statistics industry such as Baseball Prospectus, The Hardball Times, and web-darling Fangraphs all owe debts of gratitude to James and his belief baseball stats could be marketed widely and profitably distributed.

The intense interest in baseball statistics which arose during this timeframe not only enhanced the fantasy sports data revolution of the 1970's and '80's but ultimately led to millions of newly- 
designed line extensions generated from Winkenbach, Gamson, and Okrent's initial fantasy sports brands. As Christ and Anderson (2011) note, what was changing during the 1950-80's was a "strengthened consumer service and satisfaction [driven] by reducing service response time and increasing communication between salespeople and customers." In short, baseball and media brands profiting from baseball's cultural relevance were moving into an age when technologically-efficient service providers could extend MLB's new product forms. Simulated baseball games, once played in isolation, were now played by a broader spectrum of consumers and the possibility of 'owning' a team of real-life players was sufficient incentive.

\section{The Technology Era}

Coupling an expansion of fan interest with data and everquickening availability of sports statistics to a mass market from technological breakthroughs such as the World Wide Web and electronic mail led to a massive expansion of fantasy gaming. Historically speaking, the "birth" of the internet is often stated as being 1969 and it was followed with the establishment of email in 1977. But the broad commercialization of this platform did not begin until the late 1980s when greater strides in internet usability and access came about with the introduction of the World Wide Web (WWW) in 1991. This was further enhanced by Microsoft when the Seattle software and systems company rapidly inter-connected the computer marketplace in 1996.

Understandably, the use of technology in fantasy sports endured humble beginnings and Lee Eisenberg, another writer and original Rotisserie league player with Okrent, recalls marveling at his fantasy baseball statistics once being faxed to his office. At the time, this was the fastest technology for sharing statistics with a large group spread over a large geography. But the leaps to come in technology transfer would soon make faxes look like Egyptian hieroglyphics. In 1989, fantasy technology took a major step forward with Dugout Derby, a telephone based service created by Phoneworks in association with advertising agency Wakeman \& Deforest. For a minute-based fee ( $\$ 2$ for the first minute; $\$ 1.50$ for 
each subsequent minute) Dugout Derby allowed individuals to compete in rotisserie baseball over the telephone. Customers would play by placing a call, entering a credit card number, and other personal information. To perform team transactions (add, drop or trade players), the caller needed to input a special access code which was printed in 12 of the United States' major daily newspaper markets. This code changed each day in an attempt to increase newspaper subscriptions. With weekly and end of season prizes including trips, merchandise and cash, Dugout Derby attracted hundreds of thousands of managers.

During 1990, Dugout Derby received more than \$8-million worth of calls and appeared to a circulation base of 7.5-million people. Upon the introduction of Dugout Derby, the Philadelphia Inquirer expected to sign up 5,000-7,000 managers, but drew 15,058 during the first three weeks alone. Across the country, it became apparent baseball fans were quickly becoming Dugout Derby managers. Demographic data of these managers (similar to modern day fantasy players) was: $78 \%$ male, $25-49$ years old, had earned a college degree, owned their own home and regularly read the newspaper. Thanks to Dugout Derby's success, Phoneworks went on to offer similar games for the NFL (Pigskin Playoff), PGA (Fairway Fantasy), and NASCAR (Pedal to the Metal). Each line extension had incredible success in garnering callers and signing major sponsors such as Spalding and Gillette (Wojitas, 1991). Mass scale interconnection was setting the stage for the explosion of internet based fantasy sports.

The initial appeal for these fantasy sports was the internet's growing availability and immediate digital aggregation of player statistics. It made tracking league performance considerably easier (vs. relying on the next day's newspaper box scores). However, even with the availability of these statistics, managers were still forced to tabulate fantasy scoring and results manually. Rather than having the league commissioner compile these calculations in addition to facilitating transactions throughout the season, a branded internet league management system became the logical next step. In 1995, ESPN became the first major entity to offer an online version of fantasy sports on their website, ESPN SportsZone (Xiong, 1997). 
Less than two years later, on January 1, 1997, Peter Pezaris launched Commissioner.com. For $\$ 300$ per league, his company offered to eliminate the tedious work involved in managing a fantasy season. Commissioner.com was an early winner in the newly created fantasy league "hosting" market and was followed that same year by CBS Sports offering their own fantasy service beginning in 1997 (Ibid). The next year, CBS Sports officially partnered with Commissioner.com to offer fantasy games and, by 2001, purchased it outright for \$31-million. In just a few years Commissioner.com had established itself as the standard for an online fantasy sports service and warranted the attention (first) and then acquisition by a major sports network (Adams, 2003).

Just as Commissioner.com created the standard for fantasy league management, RotoNews.com set the standard for the way fantasy sports news would be disseminated. Rather than writing complete articles, RotoNews provided "player notes". Whenever a player was hurt, benched, released, signed or traded, an update was made to their respective player page. Fantasy managers could now find the latest information about players on their teams, and make informed decisions more easily (Berry, 2010). RotoNews, and its later iteration Rotowire, enjoyed numerous firsts in the fantasy industry including the internet's first free-to-use fantasy league management service (1998) and the 2004 provision of player updates to mobile phones (Rotowire, 2011). During these early years, the overall business model for fantasy league hosting services was largely pay-to-play. Companies like Commissioner, ESPN, and CBS Sports garnered all their revenue directly from the users. However, this approach would evolve and in 1999 Yahoo! became the first major entity to offer a league hosting service free of charge (Yahoo!, 1999). A strategy of relying on website advertising dollars helped Yahoo! become the most visited fantasy sports offering on the internet with FSTA President Jeff Thomas contending that by offering a free service Yahoo! became the fantasy market leader (LaMonica, 2006). 


\section{Technological Marketing}

Up until the introduction of the internet to a mass audience, fantasy statistics were tracked with newspaper box-scores leading to hand-filled-in ledger sheets. Following widespread adoption of the internet, however, scoring was tabulated digitally. This growing ease of coordinating league management, tallying results accurately and presentation of league "standings" has led to estimates suggesting more than 32-million Americans are playing in fantasy leagues and generating approximately $\$ 4$-billion of economic impact (FSTA, 2011). Understanding this rapid expansion is aided by acknowledging by data and website access through cellular and mobile phones starting in the early 2000s. It was followed by faster broadband speed (marketed heavily by numerous service providers), Wi-Fi access in public settings (promoted by retailers) and the introduction of applications (known as apps) designed for revolutionary technology brands such as Apple's iPhone and iPad. Developers of fantasy sites were quick to recognize the need for banter between users and started creating numerous features to accommodate networked dialogue. Yahoo initiated a 'smack talk' section directly into their scoreboards for each head-to-head fantasy sport they offered and some services took things even further. Bloomberg Sports hired New York Mets Hall of Famer Keith Hernandez in 2010 to record about forty videos of Hernandez talking trash about typical fantasy baseball happenings (Bloomberg Fantasy Sports, 2010). With Hernandez making wise-cracks about everything from bad trades or poor lineup decisions, to bragging about "owning" players like Phillies All-Star Chase Utley, users of Bloomberg fantasy baseball could send 'trash talk' videos to other league members, taking product engagement to the next level.

This fit a 2007 study by Farquhar and Meeds that separated fantasy sports users into five groups based on their motivations for playing. In order of size from largest to smallest the users represented were: "Casual players", who primarily participated for entertainment value, devoted less than 2 hours per week and spent less than \$20 annually on fantasy sports. "Skilled players", enjoyed the surveillance aspect of "information gathering, working with 
statistics, and staying in touch with real-world sports." They believed fantasy success stemmed from skill rather than luck.

"Isolationist thrill-seekers" were most motivated by escape from everyday life, lack of social interaction, and a need for arousal.

"Trash Talkers" had similar profile of the previous group, however with more of a need for social interaction. "Formatives" are those who do not appear to show a major motivation yet, likely due to inexperience in playing fantasy sports, and their youth (average age 20.5). Taking a simpler look at the data, the study separated the sample in to two groups. Those who were highly involved enjoyed the statistics and skill-based aspects, whereas participants with low involvement sought the thrill of victory and bragging rights (Farquhar and Meeds, 2007).

Looking at the consumption habits of fantasy managers, demographic and psychographic research shows the average participant is: male $(80 \%)$, Caucasian $(91 \%)$, holds a bachelor's degree or higher $(70 \%)$, has more than five years of internet experience (84\%), earns between $\$ 60,000-\$ 100,000(\$ 94,000$ is the average), and spends roughly $\$ 200$ annually on fantasy sports entry fees, player purchases and data reviews. Fantasy players were also stronger consumers in major product categories such as beer/alcohol, fast food, airline travel, video games, sports periodicals, athletic shoes, cell phones and credit card usage when compared to the general population (IPSOS Public Affairs, 2008). Additionally, more than $40 \%$ of these participants operated in a two-screen environment - Laptop and TV - on Sundays (World Fantasy Games, 2011). Drayer et al (2010) found that fantasy participants are likely to utilize the Internet, television, cellular telephones, and a variety of print media, (all on a locally and nationally covered scale) at much higher levels as a result of their interest and participation in fantasy football. Naturally, viewership of NFL games also increased as a result and for many users reached highest-ever levels. Interestingly, some users also reported seeking out more information on NFL player's personal lives and community involvements in response to owning them in a fantasy league (Drayer et al, 2010).

For sports leagues, this enhanced avidity and content consumption has proven beneficial. Early in the continuum of 
fantasy sports, the perception by professional leagues of fantasy participants might have held that only children or a narrow niche of statistical 'geeks' were engaged with this form of gaming. To wit, that would not have been an attractive demographic to target (at least for most traditionally-marketed consumer goods). However, research from 2011 shows fantasy sport participants wield significant spending power and has emerged as a dynamic demographic given the presence of social networks linking "league" members and the constant interaction (word-of-mouth) by these fantasy sports gamers online and offline.

Gender is also becoming a more closely examined topic in the fantasy sports world. Sport in general has long been considered the domain of men and, to little surprise, fantasy sport engagement appeared to follow the same path at first. Recently, however, there are indications of more female involvement. Male participation, the IPSOS study found, dominates but specific services report a growing percentage of category diversification via females. David Geller, director of fantasy sports at Yahoo!, said 14\% of the fantasy site's users were women, and they "have seen an upward trend". For ESPN, about $18 \%$ of its fantasy content was consumed by women, with growth in the low double digit percentages (Berr, 2009). Internet sites like Girlsfantasyfootball.com, once used the motto "For Women, By Women", to get more women involved and debunk myths regarding the difficulty of playing fantasy football. "Fantasy Football is easy and a lot of fun. You don't need to know anything about football to play fantasy football, really! It is easy to learn and easy to play. And contrary to popular belief, it doesn't take a lot of time. If you have fifteen minutes a week, you have time for Fantasy Football. The camaraderie and competition between friends, family and spouses adds to all the fun. Take the leap; you won't regret it" (GirlsFantasyFootball.com, 2011).

\section{Advertising/Sponsorship/Economics}

Fantasy football revenues including advertising ventures, sponsorship agreements and special events ultimately led to the creation of the Fantasy Sports Trade Association (FSTA) and it was 
formed precisely because of this segment's notable growth. The FSTA mission included providing "a forum for interaction between hundreds of existing and emerging companies in a unique and growing fantasy sports industry" and to "serve the small, the large, the entrepreneurs, and the corporations [as well as] the pioneers that invested in and grew the industry in the 1980's and 1990's." FSTA also claims to serve the "visionaries, innovators, investors, advertisers, and sponsors that would like to network and learn more about the exciting fantasy sports" (FSTA, 2011). With more than 100 member organizations, FSTA has secured many influential sports representatives from CBS Sports, Advance Sports Media, USA Today, STATS Inc and Rotowire. Through trade conventions, newsletters, market research, and media relations, FSTA is helping grow the fantasy sports industry and the most important aspect might be reflected in fantasy sports advertising. Between September 2010 and January 2011, Yahoo's mobile fantasy app/website saw 1.3billion ad impressions from official sponsors like Toyota and Subway. Yahoo sought to increase engagement with users, giving them more interactivity and features (Tsirulnik, 2011). Seeing online "eye-popping growth", Yahoo! knew advertisers were "shifting from mass-reach vehicles to depth-of-engagement vehicles" (Holahan, 2006).

Sponsoring fantasy games has also proven to improve awareness of a company and in 2009, The Sporting News ' main fantasy football sponsor, Castrol, saw improvement against competing motor-oil brands. This sponsorship was highly involved as The Sporting News' site was skinned with Castrol logos and its colors. Plus, TSN cleverly branded 'buttons' and site features (Eckardt, 2009). By increasing depth of engagement, Castrol's page views skyrocketed in September 2009, surprassing brand leader, Shell. The increase was largely attributed to $T S N$, as it was responsible for $12 \%$ of referrals to Castrol's site, a higher percentage than even Google searches (Merrihew, 2009). In baseball, a 2009 sponsorship success emerged when Burger King became the official sponsor of Major League Baseball's "Beat the Streak" fantasy game. The game called for users to select one player each day, trying to string together the longest streak of days with hits. If the customer's 
player went hitless, their streak went back to zero. Research after the 2009 season by Turnkey Sports \& Entertainment showed Burger

King surged to the top of consumer awareness among quick-service restaurants, ahead of Taco Bell, the official fast food sponsor of MLB (Broughton, 2009). Further, as Sports Business Daily reported, "The more prominent new advertising trend in fantasy sports is the custombuilt fantasy contest for a corporate sponsor or a game in which the sponsor itself becomes part of the content" (Fisher, 2010). Its report specifically mentioned RotoHog's development of fantasy games for GoDaddy.com, LG and Fathead; Fantasy Sports Ventures' 2009 deal with Sprint and Citizen Sports Network's project with Miller Lite for the NCAA basketball tournament.

While it has many positive aspects, fantasy related marketing or advertising can also lead to controversy. One instance occurred when the NFL used the injury of a player as the basis for an advertisement of their online fantasy football offering. The ad depicted Kansas City Chiefs running back, Jamaal Charles, shortly after he sustained a season ending ACL injury. In bold type, the ad copy read "Injury ruined your fantasy season? Start again on NFL.com." The advertisement was used to promote online fantasy leagues which begin mid-season, giving players who performed poorly in other leagues the chance to start with a clean slate (Boren, 2011). Because the NFL was theoretically profiting from an injury to one of its players, the ethics of the ad were called into question and the commercial caused a stir online where many called the ad dehumanizing. The NFL quickly issued an apology, calling the ad a 'mistake' (Nudd, 2011). A similar advertisement ran in 2010 for Sprint Wireless with a doctor attending to a fictitious pro football player with a serious knee injury. The player was shown asking what the injury would mean for him, to which the doctor responded "it means I'm dropping you from my fantasy team" (Hounsell and Galvez, 2010). This advertisement was also thought to dehumanize the player, but because it was fictitious there was not a significant response. 


\section{Conclusion}

Sports fans have historically shown a desire to get closer to their favorite sports and because of their avidity sport-themed toys or fantasy games have been developed to capitalize on this fascination. As Christ and Anderson (2006) noted, evidence suggests adopting the latest technology is a long, ongoing process that can be traced back at least to the beginning of professional personal selling in the mid-1800s. This engagement has correspondingly evolved with both the development of economic concepts such as disposable income and 'spare time' but also the creation of professional sport leagues and the invention of new game forms (such as basketball by Dr. James Naismith in 1891). The development of in-home baseball games arguably led to computer simulations where statistics were manipulated for social gaming. When those engagements were married with the internet and social networking such as Twitter, professional sport would benefit from the creation of fantasy leagues. Further, as data accessibility became more efficient to procure, it strengthened professional athlete awareness, monetization protocols and social connectivity by fans. Not surprisingly, with each technological development, fantasy gaming has grown more interactive and received increasing levels of media coverage (dedicated to fantasy gamers).

Before fantasy sports entered the mainstream, typical sports fans were likely familiar with specific teams, league superstars and perhaps a rival team's top players. Only obsessive or diehard fans of a sport were likely to learn about all the players in an entire league. These avid consumers felt a stronger connection to their favorite sport and possibly even a sense of personal investment in the sport product (rather than just acting as a passive observer). This investment has required more information about lesser known players which in turn has led to fans creating fantasy teams and joining networked leagues. Easier data acquisition has amplified attention to player statistics and contemporary technology which, in turn, has led sport practitioners to develop new revenue sources via the operation of fantasy websites, creation of on-line advertising, fantasy-related television and radio 
shows, sales of magazines and on-line subscriptions related to fantasy player evaluation.

While this work provides a contemporary history of fantasy sports, future researchers may wish to explore how fantasy sports games (or leagues) evolve and influence actual in-stadium game attendance or commitment to a single team. In particular, the changing needs of individuals to control their sporting heroes (increasingly accomplished via video games) should be of significant interest to media outlets, sports leagues, teams, individual players (and their agents) and sponsors because home team loyalties (and investments in that team) may become secondary to fielding an elite fantasy team and winning a fantasy league. Additionally, while the NFL is currently the dominant league in terms of fantasy sport popularity, this was not always the case, as baseball table games and fantasy Rotisserie-style leagues once dominated football in gaming popularity. Such shifts in cultural relevance and the transitions of what Strasser (1989, p. xi) called the "networks of human relationships as a fundamental aspect of culture" warrant a greater investigation for researchers, historians and brand marketers.

The authors wish to thank Syracuse University students Noel Byrd and Erica Belanger for their academic and technical support on this project. 


\section{Historical Development and Consumerism}

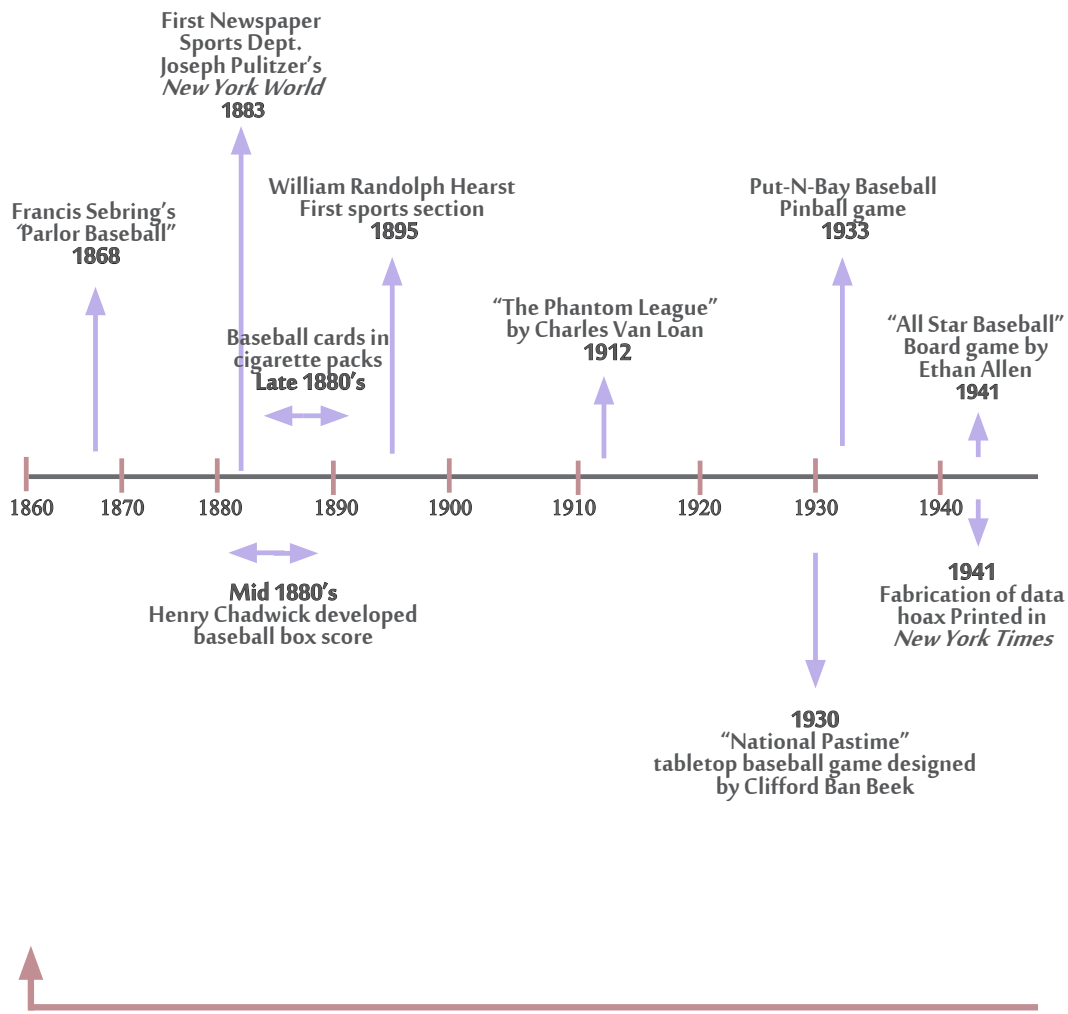

The Tabletop and Board Game Era 


\section{of Fantasy Sports Games and Leagues}

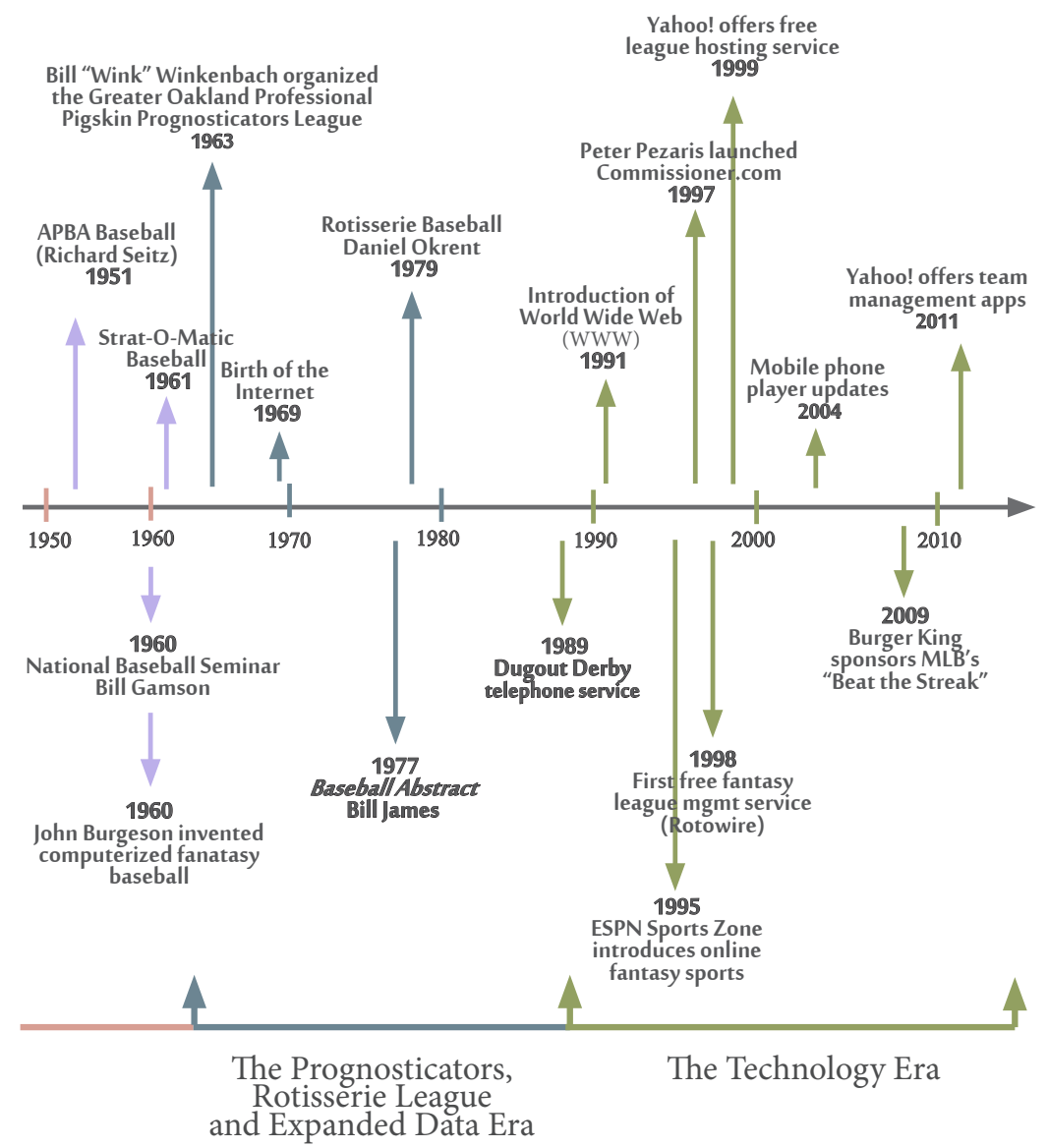




\section{References}

Aaker, D. (1991), Managing Brand Equity: Capitalizing on the Value of a Brand Name, The Free Press, New York.

Aaker, D. (1996), Building Strong Brands, The Free Press, New York.

Adams, R. (2003) "Peter Pezaris", Sports Business Daily, available at:

http://www.sportsbusinessdaily.com/Journal/Issues/2003/11/ 20031110/Forty-Under-40/Peter-Pezaris.aspx (accessed 5 November 2011).

Albert, J. and Bennett, J. (2001), Curve Ball: Baseball, Statistics, and the Role of Chance in the New Game, Copernicus/Springer-Verlag, New York, NY.

Allis, S. (2006), "Lords of the Games; Fantasy Baseball Indebted to Two Innovators", Boston Globe, March 12, A3.

APBA Games, "Company History", available at: http://www.apbagames.com/stadium/about_us/index.html.

Berr, J. (2009), "Media World: Ranks of women fantasy football players growing" DailyFinance.com, available at: . http://www.dailyfinance.com/story/media/media-worldranks-of-women-fantasy-football-playersgrowing/19125945/.

Berry, M. (2010), "Hitting the Jackpot", ESPN, available at: http://www.espn.go.com/espnmag/story? $\mathrm{id}=3288522$

Bloomberg Fantasy Sports, 2010

Boren, C. (2011), "NFL.com ad uses Jamal Charles to remind football players that he's finished this year, but they aren't", 
Washington Post, available at:

http://www.washingtonpost.com/blogs/early-lead/post/nflcom-aduses-jamaal-charles-to-remind-fantasy-football-players-that-hesfinished-this-year-but-theyarent/2011/09/22/gIQAw57DoK_blog.html (accessed 10 November 2011).

Bowman, J, Zoss, J. (1989), Diamonds in the Rough: The Untold History of Baseball, Macmillan Publishing, New York, NY.

Brock, D. (2006), "Leagues of Their Own", Nine: A Journal of Baseball History and Culture, No. 15, pp. 110-113.

Brock, D. (2010), "Twain and Crane: The Old Ball Game”, New York Times, March 14, SP2.

Broughton, D. (2009), "Gatorade, Pepsi gain in avid fan awareness; BK sees increase with fantasy game", Sports Business Journal, November 16-22, pp. 14-15.

Burton, R. (2010a), “The Author of 'Red Badge' Loved the Game More Than His Studies", New York Times, March 14, SP2.

Burton (2010b), "Syracuse and a Civil War Masterpiece", Syracuse University Magazine, Summer, 42-47.

Burton, R. and Finkel, J. (in press, 2013), "Stephen Crane: Baseball and a Red Badge", Nine.

Cooper, M (1995), Baseball Games, Schiffer Publishing, Atglen, Pa.

Christ, P. and Anderson, R. (2011), "The impact of technology on evolving roles of salespeople", Journal of Historical Research in Marketing, Vol. 2, No. 2, 173-193.

Cochran, J. (2005), “Can You Really Learn Basic Probability by Playing a Sports Board Game", The American Statistitian, No. 3, pp. 266-272. 
"Confessions of an NYU Outcast", Mushon.com, available at: http://www.mushon.com/fall08/nmrs/10/20/confessions-ofan-nyu-outcast/ (accessed 28 January 2011).

David, N., Duncan, M. (2006), "Sports Knowledge is Power:

Reinforcing Masculine Privilege through Fantasy League

Participation", Journal of Sport and Social Issues, Vol. 30

No.3, pp. 244-264.

Drayer, J., Dwyer, B., Morse, A., Shapiro, S. and White, J. (2010),

"The effects of fantasy football participation on NFL consumption: A qualitative analysis", Sport Management Review, pp. 129-141.

Dulken, S. (2002), Inventing the $19^{\text {th }}$ Century, NYU Press, New York, NY.

Dunn, K. (2009), "Fantasy Football: Increasingly a Woman's Game, Too", NPR.org, available at:

http://www.npr.org/templates/story/story.php?storyId=11281 1315 (accessed 23 March 2011).

Dwyer, B. (2013) “The Impact of Game Outcomes on Fantasy Football Participation and National Football League Media Consumption", Sport Marketing Quarterly, Vol. 22, No. 1, $33-47$.

Eckardt, D. (2009) "Castrol Scores With Sporting News Fantasy Football Sponsorship", Fantasy Ethos.com, available at: http://fantasyethos.com/2009/11/castrol-scores-withsporting-news-fantasy-football-sponsorship/ (accessed 27 February 2011).

Edelman, M. (2012), "A Short Treatise on Fantasy Sports and the Law: How America Regulates its New National Pastime", Harvard Journal of Sports \& Entertainment Law, Vol. 3, No. 1, Winter, 1-53. 
Eisenberg, L, Waggoner, G. (1984), Rotisserie League Baseball, Bantam Books, New York, NY.

Esser, L. (1994), “The Birth of Fantasy Football”, Fantasy Football Index.

Farquhar, L, Meeds, R. (2007). "Types of Fantasy Sports Users and Their Motivations", Journal of Computer-Mediated Communication, pp. 1208-1228.

Fisher, E. (2010), "Sponsorships, custom-built games boost ad sales", Sports Business Daily, available at: http://www.sportsbusinessdaily.com/Journal/Issues/2010/03/ 20100301/SBJ-In-Depth/Sponsorships-Custom-Built-GamesBoost-Ad-Sales.aspx (accessed 27 March 2011).

Fantasy Sports Trade Association (2011), "Fantasy Sports Sports Participation Sets All-Time Record, Grows Past 32 Million Players", FSTA.org, available at: http://www.fsta.org/blog/fsta-press-release/fantasy-sportsparticipation-sets-all-time-record-grows-past-32-millionplayers (accessed 10 November 2011).

Fantasy Sports Trade Association (2012), "Summer 2012 Fantasy Sports Research Group and IPSOS Study", found at: http://fsta.org/industry_demographics

Harris, B. (2003), “A Wink and a Nod to the Founders of Fantasy Football", available at: http://www.fspnet.com/wink.pdf (accessed 20 September 2011).

Holahan, C. (2006), . "Fantasy Football 2.0", Bloomberg Businessweek, available at: http://www.businessweek.com/technology/content/sep2006/t c20060901_880554.htm (accessed 20 February 2011). 
Hollander, P. (1967), "Dream Team”, found in Strange But True Football Stories, Random House, New York, edited by Z. Hollander, 74-77.

Hounsell, G, Galvez, E. (2010), "Injury”, Television Commercial, Sprint, San Francisco, CA.

Huey, A. (2005), "What if Sports Provides Surfers with Dream Matchups?", Grand Rapids Press, March 8, D2.

IPSOS Public Affairs, (2008), "Study: Fantasy Players Spend Big ", Sports Business Daily, available at:

http://www.sportsbusinessdaily.com/Journal/Issues/2008/11/ 20081117/This-Weeks-News/Study-Fantasy-Players-SpendBig.aspx (accessed 23 March 2011).

Kalb, B. (2012), "The Lost Founder of Baseball Video Games", Grantland, April 9, available at: http://www.grantland.com/story/_id/7793059/johnburgeson-ibm-computer-start-baseball-video-games

Katz, H. (2009), Double Play", Smithsonian, October, 7-8.

Kotler, P. (1991), Marketing management: Analysis, planning, implementation, and control, Prentice-Hall, Englewood Cliffs, N.J.

LaMonica, P. (2006), "Fantasy Football... real money", $C N N$ Money, available at: http://money.cnn.com/2006/08/11/news/companies/fantasyfo otball/ (accessed 10 November 2011).

Lewis, M. (2003), Moneyball, W.W. Norton, New York, NY.

McChesney, R. (1989), "Media Made Sport: A History of Sports Coverage in the United States", from Media, Sports, \& Society, Sage Publications, Newbury Park, edited by Lawrence A. Wenner, 49-69. 
McNeil, W. (2008), All-Stars for the All Time: A Sabermetric Ranking of the Major League Best, MacFarland and Company Inc. Publishers, Jefferson, NC.

Merrihew, L. (2009), "More Castrol Traffic No Fantasy", Compete.com, available at:

http://blog.compete.com/2009/11/03/more-castrol-traffic-nofantasy/ (accessed 27 February 2011).

Miller, S. (2011), Strat-O-Matic Devotees Celebrate Its $50^{\text {th }}$ Anniversary", New York Times, February 14, D5.

"Mustrash Talk", Bloomberg Fantasy Sports, available at: http://www.bloombergsports.com/fanofferings/baseball/must rash/mustrash_talk-your_sister.html (accessed 23 March 2011).

Nudd, T. (2011) "NFL.com Spikes Fantasy-Football Ad With Injured Jamaal Charles", Adweek.com,available at: http://www.adweek.com/adfreak/nflcom-spikes-fantasyfootball-ad-injured-jamaal-charles-135052 (accessed 10 November 2012).

Reilly, E. (2005), Baseball: An Encyclopedia of Popular Culture, University of Nebraska Press, New York, NY.

Rotowire (2011), available at: http://www.rotowire.com/about.htm.

Schauf, M. (2010), "Fantasy Sports History: The GOPPPL.", available at:

http://www.fantasysportsbusiness.com/wordpress/2010/08/05 /fantasy-sports-history-the-gopppl (accessed 4 October 2011).

Schwarz, A. (2004), The Numbers Game: Baseball's Lifelong Fascination with Statistics, Dunne Books, New York, NY. 
Strasser, S. (1989), Satisfaction Guaranteed, Smithsonian Books, Washington.

Tsirulnik, G. (2011), "Toyota, Subway score touchdowns with Yahoo mobile properties", Mobile Marketer, February 3, found at:

http://www.mobilemarketer.com/cms/news/advertising/8971. html.

Walker, S. (2006), Fantasyland: A Sportswriter's Obsessive Bid to Win the World's Most Ruthless Fantasy Baseball League, Penguin Publishing, New York, NY.

"What is Fantasy Football", GirlsFantasyFootball.com, available at: http://www.girlsfantasyfootball.com/what.html (10 March 2011).

Wojitas, G. (1991), "Consumer fantasies fulfill marketer's dream", Direct Marketing, available at: http://www.allbusiness.com/marketing-advertising/251530-1.html.

World Fantasy Games, Fantasy Sport Demographics, available at: http://www.worldfantasygames.com/site_flash/index-3.asp (accessed 23 March 2011).

Wulf, S. (1984), "For The Champion In The Rotisserie League, Joy Is a Yoo-Hoo Shampoo.", Sports Illustrated, 14 May, pp. 814.

Xiong, N. (1997), "Fanasy Sports Gets New Site Online,"The New York Times, available at: http://www.nytimes.com/1997/07/21/business/fantasy-sportsgets-new-site-on-the-web.html (accessed 5 November 2011). 
Fantasy Sports Leagues

(1999), "Yahoo! Sports Hits Home Run With Free Fantasy Baseball", Yahoo! Media Relations, available at: http://docs.yahoo.com/docs/pr/release273.html (accessed 10 November 2011). 